\title{
SUBVENÇÃO E ASSISTÊNCIA GOVERNAMENTAIS: UM ESTUDO NAS EMPRESAS DO SUBSETOR DE ENERGIA ELÉTRICA LISTADAS NA B3 ${ }^{1}$
}

\section{GOVERNMENT GRANT AND ASSISTANCE: A STUDY IN THE COMPANIES OF THE SUB- SECTOR OF ELECTRIC ENERGY LISTED ON B3}

\author{
Mariza Camila de Miranda \\ Especialista em Normas Internacionais de Contabilidade - IFRS (UERN) \\ Universidade do Estado do Rio Grande do Norte (UERN) \\ mariza.camila@hotmail.com \\ Rosângela Queiroz Souza Valdevino \\ Doutoranda em Administração (UNIFOR) \\ Universidade do Estado do Rio Grande do Norte (UERN) \\ rosangelaqueiroz84@yahoo.com.br \\ Adriana Martins de Oliveira \\ Doutora em Administração (PUC-PR) \\ Universidade do Estado do Rio Grande do Norte (UERN) \\ adrianamo@uol.com.br
}

\section{RESUMO}

Objetivo: Verificar a influência da Subvenção e Assistência Governamentais nas variáveis financeiras das empresas do subsetor de energia elétrica listadas na B3.

Fundamento: $O$ presente trabalho enfatiza a teoria das finanças públicas, através do reconhecimento, mensuração e evidenciação da Subvenção e Assistência Governamentais.

Método: Foram analisados os anos de 2015 e 2016, das empresas que constituem o subsetor de energia elétrica listadas na B3 e receberam subvenções e assistências governamentais, o que resultou em uma amostra de 15\% do total do setor (09 empresas). Foi adotado o procedimento documental, em que a abordagem empregada foi quantitativa e não probabilística - do tipo por julgamento quanto à técnica de amostragem. Foi utilizado o teste de correlação de Spearman.

Resultados: Verificou-se com os resultados, que no ano de 2015 não houve influência significativa, apenas fortes relações entre algumas variáveis, como o patrimônio líquido. Já no ano de 2016, houve correlação entre o recebimento de Subvenção e Assistência Governamentais com as variáveis financeiras estudadas, destacando-se a variável patrimônio líquido; a influência significativa detectada no ano de 2016 justifica-se pelos fatores: crescimento de vendas, renovação de concessões e venda de ativos.

\footnotetext{
${ }^{1}$ Artigo recebido em: 18/06/2019. Revisado por pares em: 29/03/2019. Reformulado em: 12/06/2020. Recomendado para publicação: 27/04/2020 por Karla Katiúscia Nóbrega de Almeida (Editora Adjunta). Publicado em: 07/09/2020. Organização responsável pelo periódico: UFPB
} 
Contribuições: A pesquisa tem contribuição teórica e prática. Nesse sentido, a primeira se refere ao levantamento da Subvenção e Assistência Governamentais a luz do CPC 07 (R1). De forma prática o estudo mostra como a SAG pode influenciar nas variáveis financeiras de um setor.

\section{Palavras-chave: Subvenção e Assistência Governamentais. Energia Elétrica. CPC 07.}

\section{ABSTRACT}

Objective: Check the influence of Government Grant and Assistance in the financial variables of the electricity subsector companies listed on the B3.

Foundation: This paper emphasizes the recognition, measurement and disclosure of Government Grant and Assistance.

Method: We analyzed the years 2015 and 2016 of the 60 companies that make up the electricity subsector listed on B3. It resulted in a sample of 15\% (09 companies). In this way, this study was based on a descriptive research on the objective, through a documentary procedure, in this case the approach employed was the quantitative and non-probabilistic - of the type by judgment - regarding the sampling technique. The Spearman Correlation test was used.

Results: It was verified with the results, that in the year of 2015 there was no significant influence, only strong relationships among some variables, such as the net equity. As early as 2016, there was a correlation between the receipt of Government Grant and Assistance with the financial variables studied, highlighting the variable shareholders' equity; the significant influence detected in the year 2016, is justified by the factors: sales growth, renewal of concessions and sale of assets.

Contributions: The research has the theoretical and practical contributions. In this sense, the first refers to the survey of Government Grant and Assistance in light of CPC 07 (R1). In a practical way the study shows how the SAG can influence the financial variables of a sector.

Key words: Government Grant and Assistance. Electricity. CPC 07.

\section{INTRODUÇÃO}

Com o desígnio de realizar todas as suas funções no âmbito econômico, o governo assume diversas atribuições; que vão desde a arrecadação até a alocação de recursos. Dessa forma, estudar e acompanhar as finanças públicas permite aos gestores converter as informações coletadas em dispositivos legais, por exemplo; auxilia no desenvolvimento econômico, além de criar mecanismos para um melhor atendimento das demandas sociais (Albuquerque, 2015).

As necessidades de uma sociedade, de forma bem generalista, transitam pela saúde, educação, segurança, entre outros. Para o fomento de uma nação, direta ou indiretamente, existe a participação do Estado na economia, e essa intervenção permite, entre outros objetivos, o ajustamento na aplicação de recursos, na distribuição de renda e na estabilidade econômica (Musgrave, 1976). Dessa forma, evidencia-se que no contexto do segmento público, as atividades estatais são primordiais para o aumento das benfeitorias e satisfação das necessidades coletivas. Apesar de dada relevância, é primordial atentar-se às limitações dessa intervenção pública, tendo em vista a capacidade dos atores do setor privado; o que pode ser nomeado de subsidiariedade (Cunha, 2013).

Nesse processo arrecadatório de recursos, torna-se essencial a presença da Ciência Contábil, pois segundo Ulbra (2009), é a contabilidade quem fornece de forma correta, as informações necessárias para subsidiar escolhas e decisões. Logo, configura-se como o instrumental que confere transparência e controle às ações executadas. Considerada a linguagem do mundo dos negócios, a contabilidade aliada as normas e práticas internacionais, sintetizam o reflexo de um esforço mundial para aproximar e intensificar as relações e trocas desses mercados globais (Campedelli, 2016). 
O processo de convergência das normas contábeis brasileiras aos padrões internacionais de contabilidade começou a ser debatido com o advento da Lei Federal no 11.638, de 28 de dezembro de 2007. A referida lei acabou determinando, de forma explícita, a adoção no sistema normativo brasileiro, das normas internacionais de contabilidade (Shimamoto \& Reis, 2010). Significou um relevante passo rumo à nova estrutura das demonstrações contábeis, no tocante ao registro e a divulgação. Posteriormente, demais mecanismos legais foram atualizando essa busca pela harmonia contábil; como a Lei Federal no 11.941, de 27 de maio de 2009; e as emissões de pronunciamentos técnicos pelo CPC (Comitê de Pronunciamentos Contábeis), que embora criado pela Resolução do CFC - Conselho Federal de Contabilidade - no 1.055, de 07 de outubro de 2005; suas primeiras publicações datam de 2008, justamente pela quebra de barreiras trazida pela Lei no 11.638/07.

Freire, Machado, Machado, Souza e Oliveira (2012) explicam que o Brasil passou a fazer parte do processo de convergência em virtude das sanções das leis no 11.638/07 e no 11.941/09, que alteram em parte a Lei no 6.404 de 15 de dezembro de 1976 (Lei das Sociedades Anônimas); e que esse processo de convergência foi aplicado de forma gradual, tendo seu ápice no exercício de 2010, ano em que houve obrigatoriedade de adoção das Normas Internacionais de Contabilidade pelas companhias abertas.

De acordo com a Resolução CFC no 1.055/2005 de 07 de outubro de 2005, o Comitê de Pronunciamentos Contábeis, ao longo dos anos, por meio de seus pronunciamentos técnicos, orientações e interpretações; tem objetivado estudar, preparar e emitir pronunciamentos técnicos acerca dos procedimentos e da divulgação de informações de natureza contábil; permitindo assim a emissão de normas pela entidade reguladora brasileira, respeitando a Convergência Brasileira aos padrões aceitos internacionalmente, buscando assim, a centralização e uniformização no seu processo produtivo.

Acerca disso, Zeff (2012) exemplifica que as demonstrações financeiras apresentavam discrepâncias significativas de uma nação para outra, dificultando a integração entre os mercados, tendo em vista a baixa transparência e comparabilidade das informações prestadas. Complementando esse raciocínio, Antunes, Grecco, Formigoni e Mendonça (2012) expõem que as mudanças introduzidas desde então, visavam aprimorar a compreensibilidade, relevância, confiabilidade e a comparabilidade das informações divulgadas, características que tornam a informação útil aos seus usuários.

Nesse contexto de inovações, pode-se destacar o fato de que as subvenções governamentais sofreram alterações no que tange ao seu registro. Deixaram de ser reconhecidas como reserva de capital, no patrimônio líquido, para serem contabilizadas em conta de resultado do exercício; assim, as SAGs (Subvenções e Assistências Governamentais) devem ser registradas como redução do custo do Ativo, caso se refiram a um ativo não monetário, ou, nos demais casos, como receita a ser apropriada ao Resultado (Loureiro, Gallon \& Luca, 2011).

Taveira (2009) conceitua as SAGs como sendo programas administrados e fornecidos pelo governo, nas suas três esferas - federal, estadual e/ou municipal - de forma delineada, cujo objetivo está voltado ao incremento de operações, na atratividade de investimentos e no financiamento de atividades de interesse público.

Logo, compreende-se que esse auxílio, pecuniário ou não, contribui para as empresas, na cobertura de suas despesas e, consequentemente, no atingimento de suas metas. Em se tratando do setor elétrico, Julião et al. (2013) enaltecem que o mesmo tem reconhecida relevância para os entes públicos, uma vez que esse setor é o responsável por gerar e fornecer energia para a sociedade, ou seja, através do atendimento das necessidades energéticas, acaba possibilitando a manutenção e crescimento da economia, o que por sua vez, tende a atrair o interesse do governo em subsidiar as empresas desse ramo econômico. 
Diante do contexto, surge o objetivo da pesquisa, que é verificar a influência das Subvenções e Assistências Governamentais nas variáveis financeiras das empresas do subsetor de energia elétrica listadas na B3. Dado o exposto, Formigoni (2008) explica que, quando os tributos e os incentivos fiscais geram impacto de forma relevante no resultado contábil e no patrimônio das empresas, acabam por caracterizarem-se em um campo de pesquisa pertinente, aconselhável e indispensável, nas áreas de contabilidade e gestão.

Logo, a pesquisa justifica-se pela relevância da temática abordada, no contexto empresarial e acadêmico. Loureiro et al. (2011), por exemplo, enfatizam que a SAG é um tema relevante dentro das organizações pela notabilidade dos valores, que envolvem governo e empresas; bem como pela carência de trabalhos científicos na referida área. Nesse sentido, o estudo tem contribuição teórica e prática. A primeira se refere ao levantamento da Subvenção e Assistência Governamentais à luz do CPC 07 (R1), mostrando por meio de estudos anteriores sua aplicabilidade. No que se refere à prática, a pesquisa enfatiza como a SAG pode influenciar nas variáveis financeiras do setor de energia elétrica. Nesse sentido, mostra ainda como as Subvenções e Assistências Governamentais podem dar oportunidades para uma organização crescer financeiramente e quais variáveis podem ser mais influenciadas. Assim, com o crescimento das empresas, a nação se desenvolve em aspectos sociais e econômicos, despertando o interesse do governo contribuir com o crescimento empresarial.

Desta forma o presente estudo utilizou-se de uma pesquisa descritiva quanto ao seu objetivo, adotando o procedimento documental, em que a abordagem empregada foi a quantitativa. As variáveis analisadas, por meio do programa estatístico SPSS versão 23.0 e do teste de correlação de Spearman, foram coletadas dos balanços patrimoniais e demonstrações de resultado do exercício, dos anos de 2015 e 2016, das empresas do subsetor de energia elétrica listadas no site da B3.

O trabalho está dividido em cinco partes, incluindo esta introdução. O segundo tópico trata de uma contextualização da pesquisa e versa sobre o referencial teórico. Por sua vez, o item três apresenta a metodologia, enquanto que o tópico quatro exibe os resultados dos dados da pesquisa. Por fim, apresentam-se as considerações finais no item cinco.

\section{REFERENCIAL TEÓRICO}

Esta seção versa, brevemente, acerca da teoria das finanças públicas; dos conceitos de reconhecimento, mensuração e evidenciação das Subvenções e Assistências Governamentais, e discorre acerca dos estudos anteriores que abordaram esta temática.

\subsection{Teoria das Finanças Públicas}

Com uma história longínqua e interessante, é possível enxergar a influência do sistema financeiro ao longo da existência da sociedade e de seu protagonismo na economia (Cabral, 2015). No setor público não seria diferente, pois cada vez mais ciente de sua participação enquanto financiadora e beneficiária das atividades estatais, a sociedade vem se aproximando das decisões do Estado, se informando e fortalecendo sua cidadania; atuando no controle do que é ou pode vir a ser realizado (Ferreira, Oliveira, Almeida \& Teixeira, 2016). Bianchi (2014) denomina esse processo de forma social não individualizável, isto é, em que o Estado não se configura como um ente em si, e sim como um conjunto de ações protagonizadas pelos próprios indivíduos da sociedade.

De posse desse conhecimento, fica mais evidente compreender a relevância das ações e medidas estatais fornecidas ao público, cujo intento é a satisfação das necessidades da população motivo de existência dos representantes políticos. Como reforça Sanson (2011), todas as decisões proferidas pelo setor público têm base nos interesses dos cidadãos, um esforço que paira na busca pelo melhor atendimento das demandas dos cidadãos, sejam estes, pessoas físicas ou jurídicas. 
São diversas as finalidades a serem atendidas, e percorrem a saúde, educação, segurança, saneamento e economia de uma nação, sendo este último uma das peças fundamentais para mover a engrenagem da máquina pública (Luz, Leite \& Castro, 2017). A participação do Estado na economia é estudada por um segmento da ciência econômica que recebe o nome de finanças públicas, termo este que faz menção à atividade financeira do Estado que abarca todo o processo que diz respeito à obtenção, gestão e aplicação de recursos financeiros (Crepaldi; Crepaldi, 2013).

Isto é, o objetivo principal das finanças públicas consiste em estudar a atividade fiscal que irá permitir ao governo a condução de suas atividades, uma vez que este participa direta e indiretamente de todas as relações econômicas que são realizadas. Em suma, a atuação dos poderes públicos em adquirir, gerir e aplicar os recursos financeiros, indo do custeio ao investimento de atividades, caracteriza o enfoque das finanças públicas (Albuquerque, 2015).

Oliveira (2016) frisa que a teoria das finanças públicas alude aos fundamentos do Estado e das funções de governo, que sua atuação consiste na existência de falhas no mercado, como: a existência dos bens públicos, monopólios naturais, externalidades, desenvolvimento, emprego e renda. Ou seja, torna necessária a presença do Estado, suas funções e teorias.

\subsection{Reconhecimento, mensuração e evidenciação das SAGS}

Para Tavares (2010), a contabilidade e seus fenômenos atravessam três etapas, a saber: o reconhecimento, a mensuração e a evidenciação, segundo ele, configura-se no caminho natural da Ciência Contábil, de modo que, não havendo o atendimento de uma dessas etapas, a contabilidade não consegue aplicar os critérios científicos tracejados em sua área de atuação.

De acordo com o CPC 00 (R2) (2019), reconhecimento é o processo que consiste na incorporação, ao balanço patrimonial, na demonstração do resultado ou na demonstração do resultado abrangente, de item que se encaixe na definição de elemento e que satisfaça os critérios de reconhecimento; e nesse processo de inserção, os itens deverão exprimir seu valor monetário, referido como valor contábil.

Nesse processo em que os elementos das demonstrações contábeis são determinados monetariamente, exige-se uma base de mensuração, que pode ser, por exemplo, custo histórico, valor justo ou valor de cumprimento, conforme a característica identificada dos elementos reconhecidos (CPC 00 (R1), 2019).

Por fim, "a evidenciação é o canal utilizado no processo de comunicação entre a entidade e os tomadores de decisões nas organizações como instrumento de informação" (Chagas, Araújo \& Damascena, 2011, p. 106).

Em conformidade ao Pronunciamento Técnico CPC 07 (R1) (2010) - Subvenção e Assistência Governamentais - a subvenção governamental não deverá ser reconhecida até existir razoável segurança de que alguns requisitos serão atendidos, a saber: que a entidade vai cumprir todas as condições estabelecidas e relacionadas à subvenção, e que a subvenção será recebida; uma vez que somente o recebimento não seria prova de que os quesitos exigidos teriam sido realizados. Lembrando que tal contexto aplica-se a subvenção não monetária a valor justo.

Um ativo não monetário pode representar uma subvenção governamental, como por exemplo, a entrega de terrenos para uso da entidade, caso isso ocorra, ambos - terrenos e subvenção - deverão ser reconhecidos pelo seu valor justo; apenas será registrado por seu valor nominal, na impossibilidade de verificação desse valor justo. Com isso, no balanço patrimonial, a subvenção (ativo monetário ou não) deve ser representada em conta de passivo, como receita diferida ou deduzindo o valor contábil do ativo relacionado, descrevendo-se assim as duas maneiras possíveis de se reconhecer a subvenção. A mesma deve ser reconhecida como receita durante a vida do ativo depreciável por meio de crédito à depreciação registrada como despesa no resultado. Por falar em resultado, na demonstração do resultado, a subvenção deve ser registrada no grupo de contas de 
acordo com a sua natureza, algumas vezes apresenta-se como crédito, com título de "outras receitas" ou pode vir como dedução da despesa relacionada (CPC 07 (R1), 2010).

O tópico divulgação, também chamado de evidenciação na literatura, traz os itens que devem ser expostos, caracterizando as seguintes informações: a política contábil adotada para as subvenções governamentais, abrangendo também os métodos de apresentação adotados nos demonstrativos contábeis; a natureza e extensão das subvenções ou assistências governamentais e as condições a serem regularmente satisfeitas (CPC 07 (R1), 2010).

\subsection{Subvenção e Assistência Governamentais}

O Pronunciamento Técnico CPC 07 (R1) - Subvenção e Assistência Governamentais - foi aprovado em 05 de novembro de 2010 e divulgado em 02 de dezembro do mesmo ano, datas referentes à sua $1^{\underline{a}}$ revisão, revogando assim a publicação de 2008. Foi elaborado a partir da IAS 20 Accounting for Government Grants and Disclosure of Government Assistance (BV2010), emitida pelo International Accounting Standards Board (IASB).

A adoção do pronunciamento, no que se refere aos recebimentos das subvenções e assistências governamentais tem sido uma maneira de alcançar um denominador comum entre o governo e as organizações, sejam elas públicas ou privadas. Salienta-se que as subvenções e assistências governamentais podem ser concedidas pelo âmbito municipal, estadual ou federal (Nascimento \& Santos, 2017).

O termo assistência governamental é definido pelo CPC 07 (R1) (2010) como: a ação de um governo destinada a fornecer benefício econômico específico a uma determinada entidade ou mesmo a um grupo de entidades que atendam aos critérios estabelecidos. É possível compreender que a subvenção governamental é cedida a uma entidade normalmente em troca do cumprimento passado ou futuro de certas condições relacionadas às atividades operacionais da entidade.

A subvenção governamental é caracterizada como uma assistência governamental que embora não se restrinja a natureza pecuniária, é a natureza contributiva mais comum, concedida às entidades geralmente em troca do cumprimento - passado ou futuro - de alguns requisitos que se vinculam com o exercício operacional da entidade. No entanto, transações com o governo que não se distinguem das operações normais do ente, ou ainda, aquelas que em dinheiro não se quantificam confiavelmente, não podem ser consideradas subvenções governamentais (CPC 07 (R1), 2010). A subvenção governamental também pode ser designada pelas seguintes nomenclaturas: subsídio, incentivo fiscal, doação, prêmio, entre outros (CRC-PR, 2018). Crispim (2011) explana que mediante o cumprimento de normas pré-estabelecidas e em troca de atividades operacionais, passadas ou futuras, pela entidade, o governo tem a prerrogativa de conceder recursos monetários ou não, através de transferência corrente; para tal, estes recursos devem estar disponíveis no orçamento plurianual.

\subsection{Estudos anteriores sobre as SAGs}

Com a necessidade de adequação aos padrões internacionais de normas contábeis, houveram mudanças na contabilidade brasileira, dentre as quais, às relacionadas às SAGs, com destaque para a apresentação e contabilização nas demonstrações contábeis.

Diante disso, e no intuito de apresentar um panorama sobre a temática SAG, na sequência, são apresentadas algumas pesquisas sobre subvenção e assistência governamentais, realizadas no Brasil, no período de 2011 a 2019.

O estudo de Chagas et al. (2011) objetivou verificar se as SAGs recebidas pelas OSCIPs (Organização da Sociedade Civil de Interesse Público) da Paraíba e do Rio Grande do Norte, no ano de 2008, foram evidenciadas em conformidade ao Pronunciamento Técnico 07 do CPC e a NBC T 19.4 do CFC. Os resultados apontaram que grande parte das OSCIPs evidenciam as SAGs em obe- 
diência ao CPC 07 e a NBC T 19.4; no entanto, muitas entidades ainda não o faziam. No exercício de 2008 a maior parte dos recursos obtidos pelas OSCIPs adveio de repasses do governo, assim como de doações de empresas privadas e prestação de serviços. No entanto, do total dos recursos públicos, somente $69,09 \%$ foram de subvenções governamentais, distribuídas da seguinte forma: 4,54\% entre as OSCIPs do Estado da Paraíba e 64,55\% entre as OSCIPs do Estado do Rio Grande do Norte.

Na pesquisa de Loureiro et al. (2011) o propósito era investigar a divulgação das informações e os efeitos econômicos decorrentes do reconhecimento das SAGs nas demonstrações contábeis das maiores empresas abertas no Brasil, conforme o CPC 07. Constatou-se que as empresas apresentam nível de evidenciação considerado baixo, limitando-se, em média, a 30,4\% em 2008 e a 33,3\% em 2009, dos requisitos de divulgação do CPC 07. Quanto aos efeitos econômicos, constatouse uma variação positiva da rentabilidade, especialmente do ROE (Return on Equities), e uma expressiva participação das SAGs no capital próprio das empresas dos setores Têxtil e Papel e Celulose.

Em outro estudo, Rodrigues, Silva e Faustino (2011) tinham como finalidade identificar a conformidade na evidenciação dos registros contábeis das subvenções governamentais nas empresas sediadas no Estado de Pernambuco que receberam subvenções provenientes de incentivos fiscais do IR (Imposto de Renda) e ICMS (Imposto Sobre Circulação de Mercadoria), durante o período de 2007 a 2009, com as orientações do CPC 07. Os resultados estatísticos apresentaram associações significativas com o porte da empresa e a presença de auditoria externa, e que apenas $31 \%$ das demonstrações contábeis analisadas cumpriam as orientações do CPC 07.

Na pesquisa de Julião et al. (2013) buscou-se verificar se o recebimento das subvenções governamentais tinha relação estatisticamente positiva com o lucro das empresas do setor elétrico nacional e das maiores companhias internacionais (segundo a Global Sustainable Electricity Partnership) desse mesmo setor. Após a análise realizada, concluiu-se que existe uma relação positiva entre o recebimento de subvenção governamental e a lucratividade das empresas, brasileiras e internacionais, do setor estudado. Os resultados sugeriram que as empresas que receberam subvenção tendiam a serem empresas mais lucrativas.

No trabalho de Benetti, Benetti, Utzig, Braun e Oro (2014) o objetivo do estudo foi averiguar o nível de evidenciação das SAGs das empresas que integram os setores da BM\&FBovespa em conformidade com o Pronunciamento Técnico CPC 07. Os resultados apontaram que o item mais evidenciado correspondeu à política contábil adotada pela entidade para as subvenções governamentais; que a predominância de setores correspondeu a consumo cíclico, materiais básicos e utilidade pública, no entanto, a evidenciação foi satisfatória com atendimento parcial ao Pronunciamento Técnico CPC 07.

Em um estudo realizado por Barros, Souza e Dalfior (2015) buscou analisar o grau de aplicação do CPC 07 (R1) nos procedimentos contábeis adotados pelas empresas da administração pública indireta do Estado de Minas Gerais, por meio da análise das respectivas demonstrações, ano base 2013. Na pesquisa realizada constatou-se que cada empresa elabora e divulga sua demonstração de forma independente, podendo-se concluir que as empresas da administração pública indireta do Estado de Minas Gerais, sujeitas as determinações do CPC 07 (R1), precisam fazer uma revisão dos critérios e metodologias necessários à implantação e aprimoramento destas determinações.

Já Santos, Dani e Klann (2015) investigaram se existe diferenças no nível de divulgação dos requisitos do CPC 07, nas empresas do subsetor elétrico, listadas na BM\&FBovespa, no período de 2010 a 2014. Considera-se que as 65 companhias analisadas não efetuaram o disclosure de forma satisfatória no início da adoção ao pronunciamento CPC 07, mas que, a partir do ano de 2012, evoluíram consideravelmente no nível de aderência e divulgação dos requisitos, estando em acordo 
com o pronunciamento em 2013. Concluiu-se que ocorreu uma evolução do disclosure informacional sobre subvenção e assistência governamentais, que acompanha uma tendência de aderência desse pronunciamento, em virtude das especificidades do setor.

No trabalho de Gonçalves, Nascimento e Wilbert (2016) o objetivo era analisar se as empresas abertas brasileiras que receberam subvenções governamentais apresentaram maior nível de elisão fiscal e se geraram mais riqueza para a sociedade no ano de 2014, quando comparadas as empresas que não receberam tais subvenções. Verificou-se que as empresas recebedoras de subvenções governamentais apresentaram um maior nível de elisão em relação aos tributos sobre o lucro e agregaram menos valor aos seus bens e serviços produzidos e comercializados. Contudo, tais empresas geraram um maior valor adicionado total, apresentando uma maior distribuição relativa de riqueza para pagamento de tributos $(32,44 \%)$ e de pessoal $(25,05 \%)$, justificando assim os incentivos fiscais no ano estudado.

Por sua vez, Souza, Parente, Farias e Forte (2018) buscaram verificar o teor e o nível de evidenciação das Subvenções e Assistências Governamentais (SAG) nas demonstrações contábeis de empresas brasileiras beneficiadas pela Financiadora de Estudos e Projetos [FINEP], entre os anos de 2008 e 2015. De modo que, das 1992 empresas beneficiadas no período, apenas 48 empresas eram de capital aberto, ou seja, cujas informações seriam publicadas na B3 - Brasil, Bolsa, Balcão. Observou-se que $71,2 \%$ das empresas da amostra evidenciaram o recebimento de SAG. O ano de 2009 foi o mais representativo, os outros $28,8 \%$ da amostra não demonstraram o recebimento de SAG, mas realizaram menção explícita quanto ao CPC 07.

Por fim, Carlos Filho e Wickboldt (2019) tinham como intento, analisar se existia relação entre o recebimento de subvenção governamental com a distribuição de dividendos (Payout-PO) e/ou com a geração de valor por meio do Fluxo de Caixa Livre para o Acionista (FCFE). Para tanto, foram analisadas as empresas, não financeiras, pertencentes ao IBRX100, no período de 2012 a 2016. Os resultados apontaram um aumento no montante distribuído de subvenções de, aproximadamente, $300 \%$. Em relação ao Payout-PO verificou-se que não houve vantagem significativa a favor das empresas que recebem subvenções em relação as que não recebem; já em relação ao FC$\mathrm{FE}$, infere-se que as subvenções estão contribuindo para a criação de valor para o acionista nesse quesito.

\section{METODOLOGIA}

Este tópico aborda as técnicas e procedimentos empregados para a realização do presente estudo, tendo em vista que a metodologia é um facilitador na obtenção das respostas ou soluções ao problema estudado.

A respeito do delineamento metodológico, a presente pesquisa classifica-se como descritiva quanto ao seu objetivo; documental quanto ao procedimento técnico, em relação à abordagem do problema, como quantitativa, e não probabilística - do tipo por julgamento - quanto a técnica de amostragem.

Gil (2008) caracteriza a pesquisa descritiva como aquela que utiliza primordialmente, técnicas padronizadas de coleta de dados; e mais, que descreve as características de dada população ou fenômeno, e ainda, aquela que estabelece relações entre variáveis.

Já a pesquisa documental, é para Marconi e Lakatos (2003) aquela cuja fonte de coleta dos dados associa-se as chamadas fontes primárias, isto é, está restringida aos documentos, sejam eles escritos ou não, sendo realizadas no momento em que o fato ou fenômeno ocorre ou depois.

Prodanov e Freitas (2013) explanam que a abordagem quantitativa é aquela em que tudo pode ser quantificável, para que haja classificação e análise; portanto, existe a transformação de opiniões e informações em números e a utilização de recursos e de técnicas estatísticas (percenta- 
gem, média, moda, mediana, desvio-padrão, coeficiente de correlação, análise de regressão etc.), sendo forma de abordagem empregada em variados tipos de pesquisas.

Por fim, sobre a técnica de amostragem, o presente estudo aborda a amostragem não probabilística, do tipo por julgamento. Segundo Malhotra, Rocha, Laudisio, Altheman e Borges (2005), a amostragem não probabilística consiste numa técnica que leva em consideração o julgamento pessoal do pesquisador, ou seja, não utiliza seleção aleatória; e que a modalidade por julgamento, utiliza a experiência de quem pesquisa, no momento da escolha dos itens que irão compor a amostra.

Diante do contexto, Formigoni (2008) relata existir uma correlação estatisticamente significativa entre o recebimento de subvenções na forma de incentivos fiscais e os indicadores de rentabilidade das companhias abertas brasileiras não-financeiras. Diante desta assertiva, surgem as seguintes hipóteses:

$\mathrm{H}_{0}$ - Existe influência significativa das subvenções governamentais nas variáveis financeiras do subsetor de energia elétrica nos dois anos de 2015 e 2016.

$\mathrm{H}_{1}$ - Não existe influência significativa das subvenções governamentais nas variáveis financeiras do subsetor de energia elétrica necessariamente nos dois anos de 2015 e 2016.

\subsection{População e amostra}

A população do estudo é composta por todas as empresas de capital aberto pertencentes ao subsetor de energia elétrica (integrantes do setor de utilidade pública) listadas na BM\&F Bovespa (atual B3), 2015 e 2016, anos estes escolhidos para análise, pois esses anos tinham os relatórios com informações mais consistentes das variáveis financeiras no que se refere a subvenção e assistência governamentais, dessa forma proporcionando alcançar o objetivo do trabalho. O que justifica a escolha dessa temporada. No período, o subsetor de energia elétrica era composto por 60 empresas, configurando-se como o universo da pesquisa.

Todas as empresas do subsetor de energia elétrica, listadas na BM\&FBovespa (atual B3), possuem sede no Brasil, apenas 13\% (08 empresas) possuem organizações-mães sediadas fora do país, e outros $05 \%$ (03 empresas) possuem parcerias na composição de suas organizações-mães.

Das 60 empresas do subsetor de energia elétrica, apenas 09 empresas receberam subvenções e assistências governamentais nos anos pesquisados (2015 e 2016), representando a amostra, portanto, de $15 \%$ do universo da pesquisa.

Da amostra estudada:

Quadro 01 - Identificação das Organizações-Mãe da Amostra
\begin{tabular}{|c|c|c|}
\hline No $^{\circ}$ empresas & $\mathbf{\%}$ & Org-mãe \\
\hline 03 & 33,33 & Internacional \\
\hline 01 & 11,11 & Parceria \\
\hline 05 & 55,56 & Brasileira \\
\hline & & \\
\hline Total: 09 & 100,00 & - \\
\hline
\end{tabular}

Fonte: Dados da Pesquisa (2017).

O universo da pesquisa são as 60 empresas do subsetor de energia elétrica, listadas na BM\&FBovespa, nos anos de 2015 e 2016. A amostra da pesquisa, por sua vez, foi composta pelas 09 empresas do subsetor de energia elétrica, listadas na BM\&FBovespa, nos anos de 2015 e 2016; e que receberam subvenção e assistência governamentais, as quais encontram-se listadas no Quadro 02. 


\begin{tabular}{|c|c|c|}
\hline \multicolumn{2}{|c|}{ Quadro 02 - Empresas do Subsetor de Energia Elétrica da BM\&FBovespa que receberam SAG nos anos 2015 e } \\
\hline No & RAZÃO SOCIAL & NOME DE PREGÃO \\
\hline 1 & AES ELPA S.A. & AES ELPA \\
\hline 2 & AMPLA ENERGIA E SERVICOS S.A. & AMPLA ENERG \\
\hline 3 & CEMIG DISTRIBUICAO S.A. & ELETROBRAS \\
\hline 4 & CENTRAIS ELET BRAS S.A. - ELETROBRAS \\
\hline 5 & CIA ENERGETICA DO CEARA - COELCE & CEMIG \\
\hline 6 & COELCE \\
\hline 7 & CTEEP - CIA TRANSMISSÃO ENERGIA ELÉTRICA PAULISTA & TRAN PAULIST \\
\hline 8 & EMAETROPAULO METROP. ELET. SAO PAULO S.A. & ELETROPAULO \\
\hline 9 & & EMAE \\
\hline
\end{tabular}

Fonte: BM\&FBovespa (2017).

\subsection{Coleta dos dados}

A coleta dos dados foi realizada por meio da verificação das demonstrações financeiras padronizadas - DFPs, mais especificamente, o balanço patrimonial (BP) e a demonstração do resultado do exercício (DR), publicadas no site da BM\&FBovespa (atual B3), compreendendo os anos de 2015 e de 2016 das empresas componentes do universo estudado.

O website forneceu as informações necessárias para análise, sendo estudados 240 relatórios financeiros (120 balanços patrimoniais e 120 demonstrações do resultado do exercício). Foram consideradas as seguintes variáveis: receita bruta, receita financeira, ativo total, patrimônio líquido, lucro líquido e o valor da Subvenção e Assistência Governamentais.

O decreto n⿳0 9.580, de 22 de novembro de 2018, prevê em seu art. 208 que a receita bruta abrange o produto da venda de bens nas operações de conta própria, o preço da prestação de serviços e o que fora auferido nas operações de conta alheia (Brasil, 2018). Já a receita financeira se constitui como aquela que traz benefícios e agrega valor, ou seja, são exemplos os rendimentos que são obtidos com juros, descontos recebidos, atualizações monetárias, entre outras (Reis, 2018).

De acordo com o CPC 00 (R2) (2019) o ativo resulta de eventos passados e se constitui em um recurso econômico presente controlado pela entidade, e sua totalidade inclui, portanto, a soma de todas as contas, enquanto o patrimônio líquido corresponde ao valor excedente dos ativos da entidade, isto é, depois de realizada as deduções de seus passivos.

Por sua vez, o lucro líquido será o valor final adicionado ao patrimônio líquido, isto é, diz respeito ao que foi apurado na demonstração do resultado do exercício, em que se deduz todas as despesas e/ou outros valores necessários para sua apuração, chegando ao lucro dos acionistas (Gelbcke, Santos, Iudícibus \& Martins, 2018).

Por fim, a Subvenção e Assistência Governamentais se caracterizam como sendo um auxílio e/ou amparo governamental, cuja natureza pode ser pecuniária ou não, comumente ocorrendo de forma contributiva. Concede-se a entidades que cumprirão requisitos elencados previamente e que se relacionam com suas atividades operacionais (CPC 07 (R1), 2010).

\subsection{Tratamento dos dados}

Os dados foram expressos em média e desvio padrão, bem como valores mínimos e máximos, por meio do programa estatístico SPSS (Statistical Package for Social Sciences) versão 23.0. Após análise da normalidade por Shapiro-Wilk, influências significativas do SAG com as diferentes variáveis estudadas foram obtidas por meio do teste de correlação de Spearman. Valores de $p<0,05$ foram considerados significativos. 
Desse modo, foi possível a realização de uma correlação das variáveis estudadas, em que se adotou o Coeficiente r de Spearman. Essa correlação - conhecida também por postos de Spearman consiste em uma técnica não-paramétrica em que se avalia o grau de relacionamento entre observações emparelhadas de duas variáveis, quando os dados se dispõem em postos. O coeficiente de correlação por postos de Spearman pode variar de $-1,00 \mathrm{a}+1,00$, tal como o $\mathrm{r}$ de Pearson (Corrar, Paulo \& Dias, 2009).

Dessa forma, o valor calculado explicará o grau de relacionamento entre as variáveis e se são consistentes. Quanto mais próximo de 1,00 for o resultado, indica que os dois conjuntos de dados apresentam forte grau de relacionamento; quanto mais próximo de 0 for o resultado, significa dizer que os conjuntos de postos não apresentam grau de correlação significante. Assim possibilitou-se saber a influência e o grau de relação que das empresas em relação ao recebimento de subvenção e assistência governamentais (Corrar, Paulo \& Dias, 2009).

Na sequência dessa correlação, foi realizada uma análise de conteúdo, isto é, buscou-se descrever os dados obtidos, de forma mais interpretativa, fazendo uma relação dos dados estatísticos com a literatura abordada. Como elucida Bardin (2011), a análise de conteúdo, enquanto método, caracteriza-se por ser um conjunto de técnicas de análise das comunicações, em que há utilização de procedimentos sistemáticos e objetivos de descrição do conteúdo das mensagens.

\section{ANÁLISE DOS RESULTADOS}

Esta seção apresenta quatro tabelas, em que são exibidas as variáveis financeiras estudadas; bem como a estatística descritiva das empresas, por meio das técnicas: média, desvio padrão, mínimo e máximo. Há, ainda, a análise interpretativa dos dados numéricos, obtidas com a utilização do programa Statistical Package for Social Sciences (SPSS) e o teste de correlação de Spearman; como segue:

Tabela 01 - Estatística Descritiva das Empresas (n=09). No período de 2016. Valores em R\$

\begin{tabular}{lcccc}
\hline \multicolumn{1}{c}{ Variáveis } & Média & Desvio padrão & Mínimo & Máximo \\
\hline Receita Bruta & 14.792 .274 & $19.412 .962,92$ & 206.607 & 60.748 .853 \\
Receita Financeira & $1.578 .659,889$ & $3.633 .082,608$ & 3.526 & 11.223 .390 \\
Ativos & $30.200 .332,4$ & $54.084 .136,7$ & 50.040 & 170.499 .429 \\
Patrimônio Líquido & $8.645 .950,889$ & $13.994 .699,09$ & 16.216 & 44.064 .927 \\
Lucro & $1.054 .607,778$ & $1.842 .211,394$ & 0 & 4.949 .334 \\
SAG & $1.118 .999,444$ & $2.309 .517,167$ & 0 & 7.077 .355 \\
\hline
\end{tabular}

Fonte: Dados da Pesquisa (2017).

Tabela 02 - Estatística Descritiva das Empresas (n=09). No período de 2015. Valores em R\$

\begin{tabular}{lcccc}
\hline \multicolumn{1}{c}{ Variáveis } & Média & Desvio padrão & Mínimo & Máximo \\
\hline Receita Bruta & $11.482 .740,5$ & $11.247 .939,26$ & 198.444 & 32.588 .838 \\
Receita Financeira & $2.284 .088,333$ & $5.881 .652,766$ & 3.334 & 17.952 .241 \\
Ativos & $28.300 .643,33$ & $46.934 .747,2$ & 1.098 .255 & 149.645 .408 \\
Patrimônio Líquido & $8.275 .803,222$ & $13.052 .013,49$ & 760.707 & 41.739 .222 \\
Lucro & $437.186,111$ & $784.928,038$ & 0 & 2.469 .003 \\
SAG & $2.470 .379,667$ & $6.322 .683,606$ & 2.427 & 19.258 .527 \\
\hline
\end{tabular}

Fonte: Dados da Pesquisa (2017).

Diante das tabelas 01 e 02 é possível observar que a média das subvenções governamentais foi de 1.118.999,444 em 2016, com desvio padrão $(2.309 .517,167)$. No entanto, em 2015 a média de 
subvenções investidas nas empresas foi maior em $2.470 .379,667$, com desvio padrão $(6.322 .683,606)$. Com isso, foi possível identificar o coeficiente de variação ( $\mathrm{CV} \%)$, que se trata do desvio padrão sobre a média (Corrar, Paulo \& Dias, 2009).

Neste sentido, mostrou-se que CV\% em 2016 foi 206 e em 2015 de 255. Ainda segundo Corrar, Paulo e Dias (2009) quando o coeficiente de variação for maior que 30, significa dizer que existe alta variabilidade entre as médias, principalmente em 2015 , tendo vista assim que as empresas não são homogêneas.

Ainda foi possível averiguar que o menor valor recebido pelas empresas em subvenções nos anos de 2016 e 2015 foi na variável lucro, representado por 0. No que se refere ao máximo recebido de subvenções governamentais pelas organizações em 2016 foi de 170.499 .429 e 149.645 .408 em 2015, tais valores representados nos ativos dos respectivos períodos.

Explicitando o que Oliveira (2016) ressalta, da necessidade de presença do Estado nas falhas de mercado, mais especificamente no item desenvolvimento, tendo em vista que a maior representatividade obtida foi no valor dos ativos e este se configura como os bens adquiridos, construídos e/ou obtidos por doação, que possam conferir expectativas de benefícios futuros às entidades (Iudícibus, 2000). Corroborando com os resultados Julião et al. (2013) reconhecem que o setor elétrico tem relevância para os entes públicos, uma vez que esse setor é o responsável por gerar e fornecer energia para a sociedade, ou seja, por meio do atendimento das necessidades energéticas, acaba possibilitando a manutenção e crescimento da economia, nesse sentido, tende a atrair o interesse do governo em subsidiar as empresas desse ramo econômico.

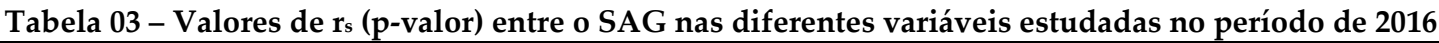

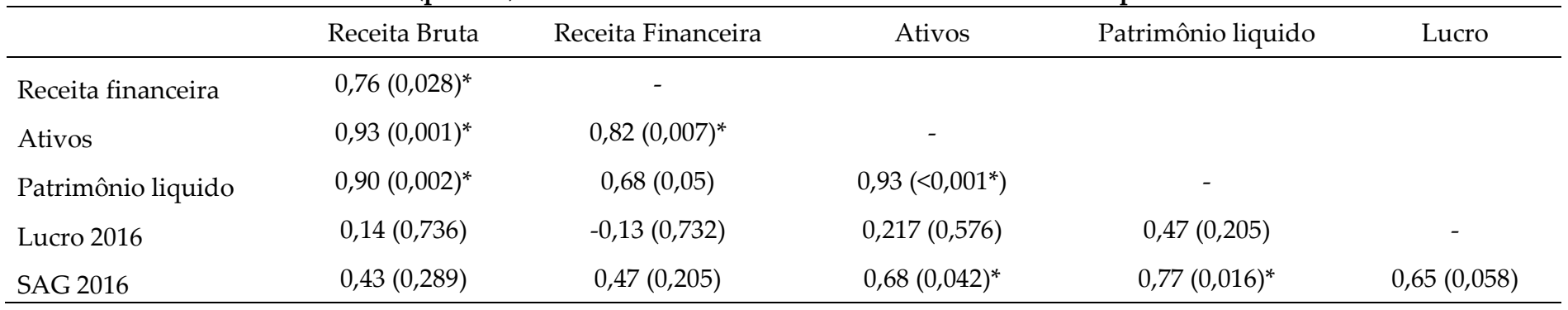

*Significância estatística ( $\mathrm{p}<0,05$ - Spearman). Fonte: Dados da Pesquisa (2017).

A tabela 03 mostra que em 2016 houve forte correlação entre o SAG e as variáveis estudadas. A variável que mais se destaca com o recebimento das subvenções é o patrimônio líquido em 0,77, pois segundo Hair, Black, Babin Anderson e Tatham (2009) a correção acima de 0,6 representa-se como forte.

Diante desse contexto Crepaldi e Crepaldi (2013) relatam que a influência financeira do Estado nas empresas é fundamental para o crescimento nacional, tendo em vista que quando as organizações se destacam, a nação cresce em termos sociais e financeiros. Com isso, Formigoni (2008) explica que, quando os tributos e os incentivos fiscais geram impacto de forma relevante no resultado contábil e no patrimônio das empresas, acabam por caracterizarem-se em um campo de pesquisa pertinente, aconselhável e indispensável, nas áreas de contabilidade e gestão. 
Tabela 04 - Valores de rs (p-valor) entre o SAG nas diferentes variáveis estudadas no período de 2015

\begin{tabular}{|c|c|c|c|c|c|}
\hline & Receita Bruta & Receita Financeira & Ativos & Patrimônio liquido & Lucro \\
\hline Receita financeira & $0,98(<0,001)^{*}$ & - & & & \\
\hline Ativos & $0,95(<0,001)^{*}$ & $0,73(0,025)^{*}$ & - & & \\
\hline Patrimônio liquido & $0,76(0,028)^{*}$ & $0,50(0,170)$ & $0,78(0,013)^{*}$ & - & \\
\hline Lucro 2015 & $-0,095(0,823)$ & $0,07(0,865)$ & $-0,07(0,865)$ & $0,08(0,831)$ & - \\
\hline SAG 2015 & $0,26(0,531)$ & $0,50(0,170)$ & $0,23(0,546)$ & $0,47(0,205)$ & $\begin{array}{c}0,27 \\
(0,488)\end{array}$ \\
\hline
\end{tabular}

*Significância estatística ( $\mathrm{p}<0,05$ - Spearman).

Fonte: Dados da Pesquisa (2017).

Na tabela 04 percebe-se que não houve influência significativa em 2015 das subvenções concedidas às organizações, mas houve correlações diretamente proporcionais em patrimônio líquido e ativos de 0,78, entre ativos e receita financeira de 0,73 e entre patrimônio líquido e receita bruta de 0,76 . Esses pontos foram destacados pois apresentaram forte correlação entre si, pois para Hair et al. (2009) quando a correlação é apresenta acima de 0,6 é considerada forte.

Certamente essa ausência de influência significativa, no ano de 2015, pode ser explicada por alguns fatores qualitativos, que desenharam um cenário de dificuldades no ano mencionado. De acordo com Sales (2016), o ano de 2015 para o setor elétrico ficou caracterizado como o "fundo do poço", em virtude de diversas condições, tais como: recordes de aumentos na conta de luz, alta taxa de judicialização do setor, pressão sobre o caixa das concessionárias de distribuição, frustação nos leilões de transmissão (não tiveram ofertantes) e os inúmeros casos de corrupção em estatais de energia.

Embora tenha havido crescimento na receita das empresas do setor de energia elétrica de 11,9\% em 2015 (na comparação com o ano anterior); a dívida total bruta do setor atingiu R $\$ 147,4$ bilhões no fechamento de 2015, o maior valor desde 2009. Em 6 anos, a dívida do setor aumentou 85,6\%. Na comparação com 2014 ( $\mathrm{R}$ 129,8 bilhões), o endividamento das empresas do setor cresceu, portanto 13,5\% (Economática, 2016).

Já com relação a 2016, cuja influência significativa foi constatada, pode-se destacar que o desempenho do setor elétrico melhorou, uma vez que as vendas cresceram um pouco acima da inflação $(11,39 \%)$ e houve aumento extraordinário dos resultados $(905,02 \%)$, favorecido pela renovação de concessões e venda de ativos (Dias, 2017).

\section{CONSIDERAÇÕES FINAIS}

A presente pesquisa teve por objetivo verificar como as subvenções governamentais influenciaram nas variáveis financeiras das empresas do subsetor de energia elétrica listadas na BM\&FBovespa (atual B3). Para tal finalidade, analisaram-se os demonstrativos financeiros do referido subsetor, mais precisamente os balanços patrimoniais e as demonstrações do resultado do exercício das 09 empresas do setor que receberam, nos anos de 2015 e 2016, subvenção e assistência governamentais.

Constatou-se que no ano de 2015 não houve influência significativa entre a concessão de subvenção e assistência governamentais com as demais variáveis financeiras analisadas, apesar disso, foi detectada correlação entre patrimônio líquido e ativos $(0,78)$; patrimônio líquido e receita bruta $(0,76)$; e entre ativos e receita financeira $(0,73)$; uma vez que, acima de 0,6 a correlação já é considerada forte.

Contudo, no ano de 2016, evidenciou-se a influência significativa, com significância estatística de 0,016; em que a relação subvenção e assistência governamentais com a variável patrimônio líquido resultou em 0,77. Entre as próprias variáveis financeiras, pode-se destacar, novamente, a correlação entre: patrimônio líquido e ativos $(0,93)$; patrimônio líquido e receita bruta $(0,90)$; e en- 
tre ativos e receita financeira $(0,82)$; constituindo uma correlação até maior que a do ano anterior, tendo em vista a proximidade do resultado de 1,00 .

Diante dos resultados desta pesquisa, pode-se inferir que há uma relação significativa entre a rentabilidade das empresas e o recebimento de subvenção e assistência governamentais, pois os resultados referentes ao patrimônio líquido demonstraram destaque, principalmente em 2016, sugerindo que as empresas que recebem subvenção e assistência governamentais tendem a ser empresas mais rentáveis.

Os seguintes fatores qualitativos podem ter contribuído para que tal cenário fosse válido: vendas cresceram um pouco acima da inflação (11,39\%) e houve aumento extraordinário dos resultados $(905,02 \%)$, favorecido pela renovação de concessões e vendas de ativos. Diante desse contexto, a pesquisa mostra como o governo pode influenciar na rentabilidade de empresas de um setor, e isso consequentemente influência nas questões sociais e econômicas, impulsionando a organização a pensar sempre em estratégias gerenciais para manter a empresa rentável.

Como contribuição teórica o estudo apresenta o CPC 07 (R1) mostrando como a subvenção e assistência governamentais podem afetar um setor na economia. No que se refere a contribuição prática a pesquisa enfatiza como o setor de energia elétrica foi influenciado pelo governo em termos financeiros e como isso pode impactar no crescimento do setor.

O presente estudo limita-se na definição da amostra, que se apresenta em um número reduzido, permitindo assim, considerar os resultados encontrados apenas para as empresas em questão.

Os resultados apresentados referem-se apenas ao subsetor de energia elétrica, pertencentes ao setor utilidade pública da BM\&FBovespa (atual B3). Deste modo, dada a relevância do tema e da produção científica, recomenda-se a realização de outras pesquisas, com outros segmentos subvencionados da economia brasileira, isoladamente ou de forma comparativa entre seus subsetores e/ou setores.

\section{REFERÊNCIAS}

Albuquerque, A. A. de (2015). Teoria das Finanças Públicas [Programa Nacional de Formação em Administração Pública]. Brasília: Capes/UAB. Recuperado em 01 abril, 2020, de https://educapes.capes.gov.br/bitstream/capes/401400/1/PNAP-Bacharelado-

Teoria_das_Financas_Publicas-GRAFICA.pdf.

Antunes, M. T. P., Grecco, M. C. P., Formigoni, H., \& Mendoça, O. R. de, Neto (2012). A adoção no Brasil das normas internacionais de contabilidade IFRS: o processo e seus impactos na qualidade da informação contábil. Revista de Economia \& Relações Internacionais - 10 (20), 5-19. Recuperado em 24 maio, 2017, de http://www.faap.br/pdf/faculdades/economia/revistas/cienciaseconomicas/revista_economia_20.pdf.

Bardin, L. (2011). Análise de Conteúdo. 70. ed. São Paulo: ISBN.

Barros, E. L., Souza, C. A., \& Dalfior, V. A. O. (2015, outubro). Aplicação do CPC 07(R1) - Subvenção e Assistência Governamentais em empresas da administração pública indireta do Estado de Minas Gerais. Anais do XII Simpósio de Excelência em Gestão e Tecnologia - SEGeT, Resende, Rio de Janeiro, Brasil, 07. Recuperado de https://www.aedb.br/seget/arquivos/artigos15/512241.pdf.

Benetti, K., Benetti, K., Braun, M., Oro, I. M., \& Utzig, M. J. S. (2014). Evidenciação de Subvenção e Assistência Governamentais das empresas na BM\&Fbovespa. RECFin - Revista Evidenciação Contábil \& Finanças, 2 (1), 75-90. Recuperado em 22 maio, 2017 de http://periodicos.ufpb.br/index.php/recfin/article/view/17012.

Brasil. (2005). Resolução CFC ñ 1.055/2005 de 07 de outubro de 2005. Cria o Comitê de Pronunciamentos Contábeis - (CPC), e dá outras providências. Recuperado em 24 maio, 2017, de http://www.portaldecontabilidade.com.br/legislacao/cfc1055.htm. 
. (2018). Decreto $n^{0}$ 9.580/2018 de 22 de novembro de 2018. Regulamenta a tributação, a fiscalização, a arrecadação e a administração do Imposto sobre a Renda e Proventos de Qualquer Natureza. Recuperado em 05 abril, 2020, de http://www.planalto.gov.br/ccivil_03/_Ato20152018/2018/Decreto/D9580.htm\#art4.

Bianchi, A. (2014). O Conceito de Estado em Max Weber. Lua Nova. São Paulo, p. 79-104, no 92. Recuperado em 02 abril, 2020, de http://www.scielo.br/pdf/ln/n92/a04n92.pdf.

Cabral, M. (2015). Finanças: quando surgiram e como podem se aliar à sustentabilidade. Recuperado em 09 abril, 2020, de http://www.p22on.com.br/2015/11/30/financas-quando-surgiram-e-comopodem-se-aliar-a-sustentabilidade/.

Campedelli, L. R. (2016). Aspectos Tributários da Implementação das Normas Internacionais de Contabilidade (IFRS) no Brasil: uma nova abordagem a partir da perspectiva do Direito e Desenvolvimento. Dissertação de Mestrado Acadêmico em Direito. Fundação Getúlio Vargas, São Paulo, Brasil. Disponível:

https://bibliotecadigital.fgv.br/dspace/bitstream/handle/10438/16243/Dissertac\%CC\%A7a\%CC\% 83o_Laura_Versa\%CC\%83o\%20Final.pdf.

Carlos Filho, F. A., \& Wickboldt, L. A. (2019). Criação de Valor: um estudo com foco na concessão de subvenção governamental. Enfoque: Reflexão Contábil, 38(2). Recuperado em 25 maio, 2020, de http://www.periodicos.uem.br/ojs/index.php/Enfoque/article/view/41720.

Chagas, M. J. R., Araúo, A. O., \& Damascena, L. G. (2011). Evidenciação das Subvenções e Assistências Governamentais recebidas pelas OSCIPs: uma análise empírica nos estados da Paraíba e do Rio Grande do Norte. (p. 106). Revista Ambiente Contábil, 3(2). Recuperado em 21 maio, 2017, de https://periodicos.ufrn.br/ambiente/article/view/1359/1062.

Comitê de Pronunciamentos Contábeis (CPC). (2019). Pronunciamento Técnico CPC 00 (R2) - Estrutura Conceitual para Relatório Financeiro. Recuperado em 05 abril, 2020, de http://static.cpc.aatb.com.br/Documentos/573_CPC00(R2).pdf.

. (2010). Pronunciamento Técnico CPC 07 (R1) - Subvenção e Assistência Governamentais. Recuperado em 24 maio, 2017, de

http://static.cpc.mediagroup.com.br/Documentos/167_CPC_07_R1_rev\%2003.pdf.

CRC-PR. (2018). Conselho Regional de Contabilidade do Paraná. Tratamento contábil e tributário das subvenções e assistências governamentais aplicadas as entidades governamentais aplicadas a as entidades cooperativas. 1. ed. Recuperado em 09 abril, 2020,

de https://www.crcpr.org.br/new/content/download/2018_06_28_tratamento_contabil.pdf.

Corrar, L. J.; Paulo, E., \& Dias, J. M. Filho. (2009). Análise multivariada: para os cursos de administração, ciências contábeis e economia. 1. ed. São Paulo: Atlas.

Crepaldi, S. A., \& Crepaldi, G. S. (2013). Orçamento público: planejamento, elaboração e controle. 1. ed. São Paulo: Saraiva.

Crispim, G. (2011). Subvenção Governamental sob a ótica do CPC 07: Reconhecimento contábil após a Lei 11.638/2007 nas entidades privadas no Estado de Pernambuco. Dissertação Mestrado em Ciências Contábeis, Universidade Federal de Pernambuco, Recife, Brasil. Disponível: http://repositorio.ufpe.br/handle/123456789/5037.

Cunha, C. E. B. (2013). A subsidiariedade como vetor objetivo de restrição à intervenção regulatória do estado na economia: definição e instrumentalização. Dissertação Mestrado em Direito, Universidade de São Paulo, São Paulo, SP, Brasil. Disponível: https://teses.usp.br/teses/disponiveis/2/2134/tde04092014-140205/publico/Carlos_Eduardo_Bergamini_da_Cunha_integral.pdf.

Dias, L. G. (2017). Setor de Energia Elétrica: Indenizações e venda de ativos distorceram os resultados do setor. Recuperado em 26 fevereiro, 2018, de http://www.sabe.com.br/blog/detalhe/setor-deenergia-eletrica-indenizacoes-e-venda-de-ativos-distorceram-os-resultados-do-setor. 
Economática. (2016). Setor de Energia Elétrica - Vendas, Lucro, Dívida e Valor de mercado últimos 7 anos. Recuperado em 25 fevereiro, 2018, de https://economatica.com/estudos/data/20160415a.pdf.

Ferreira, R. N., Oliveira, A. S., Almeida, M. S., \& Teixeira, E. A. (2016). A importância do controle social na gestão dos recursos públicos. Anais do XIII Simpósio de Excelência em Gestão e Tecnologia - SEGeT, Resende, Rio de Janeiro, Brasil, 08. Recuperado de https://www.aedb.br/seget/arquivos/artigos16/21324209.pdf.

Formigoni, H. (2008). A influência dos incentivos fiscais sobre a estrutura de capital e a rentabilidade das companhias abertas brasileiras não financeiras. Tese em Ciências Contábeis. Universidade de São Paulo, São Paulo, SP, Brasil. Disponível: http://www.teses.usp.br/teses/disponiveis/12/12136/tde-13012009-155610/pt-br.php.

Freire, M. D. M., Machado, M. R. R., Machado, L. S., Souza, E. S., \& Oliveira, J. J. (2012). Aderência às Normas Internacionais de Contabilidade pelas Empresas Brasileiras. RCO - Revista de Contabilidade e Organizações, 6 (15), 03-22. Recuperado em 12 fevereiro, 2018, de https://www.revistas.usp.br/rco/article/download/52654/56538.

Gelbcke, E.R., Santos, A. dos, Iudícibus, S. de, \& Martins, E. (2018). Manual de Contabilidade Societária: aplicável a todas as sociedades de acordo com as normas internacionais e do CPC. 3. ed. São Paulo: Atlas.

Gil, A. C. (2008). Métodos e Técnicas de Pesquisa Social. 6. ed. São Paulo: Atlas.

Gonçalves, R. S., Nascimento, G. G., \& Wilbert, M. D. (2016). Os efeitos da Subvenção Governamental frente à elisão fiscal e a geração de riqueza. RCCC - Revista Catarinense da Ciência Contábil, 15 (45), 34-48. Recuperado em 21 maio, 2017, de http://revista.crcsc.org.br/index.php/CRCSC/article/view/2246.

Hair, J. F. Jr., Black, W. C.; Babin, B. J., Anderson, R. E., \& Tatham, R. L. (2009). Análise multivariada de dados. 6 ed. Porto Alegre: Bookman.

Iudícibus, S. de. (2000). Teoria da Contabilidade. 6.ed. São Paulo: Atlas.

Julião, C. M., Lagioia, U. C. T., Carlos, F. de A., Filho., Araújo, J. G. de., Silva, L. L. da, Filho., \& Silva, I. E. M. (2013). Um estudo sobre a correlação entre o recebimento de subvenções governamentais e o lucro das empresas nacionais, e das maiores internacionais, do setor elétrico. Revista Uniabeu. 6(14), 173-189. Recuperado em 24 maio, 2017, de http://revista.uniabeu.edu.br/index.php/RU/article/view/1007/0.

Loureiro, D. Q., Gallon, A. V., \& Luca, M. M. M. (2011). Subvenções e Assistências Governamentais (SAG): Evidenciação e rentabilidade das maiores empresas brasileiras. RCO - Revista de Contabilidade e Organizações. 5(13), 34-54. Recuperado em 22 maio, 2017, de https://www.revistas.usp.br/rco/article/view/34803.

Luz, R. S., Leite, L. L., \& Castro, F. R. A. (2017). O papel do estado na sociedade: breves considerações e perspectivas acerca da intervenção estatal. Anais da VIII Jornada Internacional de Políticas Públicas, São Luís, Maranhão, Brasil, 08. Recuperado em 09 abril, 2020, de http://www.joinpp.ufma.br/jornadas/joinpp2017/pdfs/eixo1/opapeldoestadonasociedade.pdf.

Malhotra, N. K., Rocha, I., Laudisio, M. C., Altheman, E., \& Borges, F. M. (2005). Introdução à Pesquisa de Marketing. 1. ed. São Paulo: Pearson.

Marconi, M. A., \& Lakatos, E. M. (2003). Fundamentos de Metodologia Científica. 5. ed. São Paulo: Atlas.

Musgrave, R. A. (1976). Teoria das Finanças Públicas: um estudo de economia governamental. São Paulo: Atlas.

Nascimento, L. M. B., \& Santos, L. M. S. (2017, setembro). Subvenção e Assistência Governamentais: Um Estudo nas Empresas da Construção Civil Listadas na BM\&FBOVESPA. Anais do Congresso UFPE de Ciências Contábeis, Recife, Pernambuco, Brasil, 11. Recuperado de https://periodicos.ufpe.br/revistas/SUCC/article/view/22971. 
Oliveira, J. J. (2016). A Teoria das Finanças Públicas. Recuperado em 09 abril, 2020, de https://diariodegoias.com.br/teoria-das-financas-publicas/.

Prodanov, C. C., \& Freitas, E. C. (2013). Metodologia do Trabalho Científico: Métodos e Técnicas da Pesquisa e do Trabalho Acadêmico. 2. ed. Novo Hamburgo: Feevale. Recuperado em 26 janeiro, 2018, de http://www.feevale.br/Comum/midias/8807f05a-14d0-4d5b-b1ad-1538f3aef538/Ebook\%20Metodologia\%20do\%20Trabalho\%20Cientifico.pdf.

Reis, T. (2018). Receita Financeira: entenda o que é e como ela pode ajudar um negócio. Recuperado em 05 abril, 2020, de https://www.sunoresearch.com.br/artigos/receita-financeira/.

Rodrigues, R. N., Silva, G. C., \& Faustino, O. C. (2011). Subvenção e Assistência Governamental sob a ótica do CPC 07: Reconhecimento contábil após a Lei 11.638/2007 nas entidades privadas no estado de Pernambuco. Recont - Registro Contábil, 2(3), 46-64. Recuperado em 21 maio, 2017, de http://www.seer.ufal.br/index.php/registrocontabil/article/view/507.

Sales, C. J. D. (2016). O setor elétrico brasileiro em 2016. Portal Fato Online. Instituto Acende Brasil. Jan/2016. Recuperado em 25 fevereiro, 2018, de http://www.acendebrasil.com.br/media/artigos/20160107_PortalFatoOnline_OSetorEletricoBrasi leiroEm2016.pdf.

Sanson, J. R. (2011). Teoria das Finanças Públicas. [Bacharelado em Administração Pública]. Brasília: Capes/UAB. Recuperado em 09 abril, 2020, de http://www.ead.uepb.edu.br/arquivos/Livros_UEPB_053_2012/06teorias\%20das\%20finan\%E7as\%20publicas/Livro_grafica\%20teoria\%20finan\%E7as\%20publicas.pdf.

Santos, A. C., Dani, A. C., \& Klann, R. C. (2015). Análise da evolução da divulgação dos requisitos do CPC 07 por empresas reguladas do setor elétrico listadas na BM\&FBOVESPA. Recont - Registro Contábil. 6(2), 91-109. Recuperado em 24 maio, 2017, de

http://www.seer.ufal.br/index.php/registrocontabil/article/view/1312.

Shimamoto, L. S., \& Reis, L. G. dos (2010). Convergência às Normas Internacionais de Contabilidade: uma análise sob a perspectiva dos profissionais contabilistas. Revista de Estudos Contábeis, (1) 1, 90-105. Recuperado em 24 maio, 2017, de http://www.uel.br/revistas/uel/index.php/rec/article/download/9403/8153>. Acesso em: 24 mai. 2017.

Souza, J. L., Parente, P. H. N., Farias, I. F., \& Forte, H. C. (2018). Subvenção e Assistência Governamental em empresas brasileiras com fomento à inovação da FINEP. RCCC - Revista Catarinense da Ciência Contábil, 17(51), 108-122. Recuperado em 25 maio, 2020, de http://revista.crcsc.org.br/index.php/CRCSC/article/view/2565.

Tavares, M. F. N. (2010). Reconhecimento, Mensuração e Evidenciação Contábil: Um estudo sobre o nível de conformidade das empresas listadas na Bovespa com o CPC 01 - Redução ao Valor Recuperável de Ativos. Dissertação de Mestrado Acadêmico em Ciências Contábeis. Universidade Federal de Pernambuco, Recife, Brasil. Disponível: repositorio.ufpe.br/handle/123456789/5129.

Taveira, J. H. P. S. (2009). Conformidade do Disclosure das Subvenções Governamentais nas empresas de Capital Aberto. (Dissertação de Mestrado Profissionalizante em Administração). Faculdade de Economia e Finanças IBMEC, Rio de Janeiro, RJ. Brasil. Disponível: http://livros01.livrosgratis.com.br/cp135775.pdf.

Ulbra. (2009). Universidade Luterana do Brasil. Estrutura e análise das demonstrações contábeis. Curitiba: Editora Ibpex.

Zeff, S. A. (2012). The evolution of the IASC into the IASB and the Challenges it Faces. The Accounting Review, 87(03), 807-837. Recuperado em 27 maio, 2020, de http://www.ruf.rice.edu/ sazeff/Evolution\%20The\%20Accounting\%20Review.pdf. 